\title{
EFEKTIVITAS PENGGUNAAN MODEL PEMBELAJARAN DISCOVERY LEARNING TERHADAP HASIL BELAJAR MAHASISWA MATA KULIAH KALKULUS PEUBAH BANYAK
}

\author{
Sri Wahyuni \\ Universitas Muhammadiyah Sumatera Utara \\ sriwahyuni@umsu.ac.id
}

\begin{abstract}
Student activity will affect effectiveness for student learning outcomes. The effectiveness of learning consists of four indicators, namely the quality of instruction, the suitability appropriate level of instruction, incentive, and time. The purpose of this study is to: (1) Know how the effectiveness of student learning outcomes in variable calculus subjects after getting learning with discovery learning learning models. (2) Knowing whether there is an increase in student learning outcomes in many variable calculus subjects after getting learning with discovery learning learning models. The data analysis techniques are carried out from the data description test stage, then the prerequisite test is the normality and linearity test, then test the hypothesis. The steps in the study are as follows: (1) The researcher provides a stimulus for the sample class, namely the discovery learning model; (2) At the time of the learning process the partner lecturers see the activity, student learning; (3) Provide essay tests to see the level of success of students in learning; (4) Perform statistical tests to see the effectiveness of student learning outcomes using discovery learning learning models. The results of this study are that there is an effect on the effectiveness of mathematics learning using the discovery learning model of student learning outcomes in many variable calculus subjects, and there is an increase in student learning outcomes after learning with discovery learning models of many variable calculus subjects as much as 20.53 .
\end{abstract}

Keywords: Discovery Learning, Learning Outcomes, Calculus

\begin{abstract}
Abstrak. Aktifnya mahasiswa akan mempengaruhi keefektivan untuk hasil belajar mahasiswa. Keefektifan pembelajaran terdiri dari empat indikator, yaitu kualitas pembelajaran, kesesuaian tingkat pembelajaran, insentif, dan waktu. Adapun tujuan penelitian ini untuk: (1) Mengetahui bagaimanakah efektifitas hasil belajar mahasiswa mata kuliah kalkulus peubah banyak setelah mendapatkan pembelajaran dengan model pembelajaran discovery learning. (2) Mengetahui apakah terdapat peningkatan hasil belajar mahasiswa mata kuliah kalkulus peubah banyak setelah mendapatkan pembelajaran dengan model pembelajaran discovery learning. Adapun teknik analisis data dilakukan dari tahapan uji deskripsi data, selanjutnya uji prasyarat yaitu uji normalitas dan kelinieritasan, kemudian uji hipotesis. Langkah-langkah dalam penelitian adalah sebagai berikut: (1) Peneliti memberikan stimulus untuk kelas sample yaitu dengan model pembelajaran discovery learning; (2) Pada saat poses pembelajaran dosen mitra melihat keaktifan, belajar mahasiswa; (3) Memberikan tes essay untuk melihat tingkat keberhasilan mahasiswa dalam pembelajaran; (4) Melakukan uji statistik untuk melihat keefektivan hasil belajar mahasiswa menggunakan model pembelajaran discovery learning. Hasil penelitian ini yaitu terdapat pengaruh terdapat efektivitas pembelajaran matematika menggunakan Model discovery learning terhadap hasil belajar mahasiswa mata kuliah kalkulus peubah banyak, dan terdapat peningkatan hasil belajar mahasiswa setelah mendapatkan pembelajaran dengan model discovery learning mata kuliah kalkulus peubah banyak yaitu sebanyak 20,53.
\end{abstract}

Kata Kunci: Discovery Learning, Hasil Belajar, Kalkulus Peubah Banyak

\section{PENDAHULUAN}

Proses pembelajaran di Perguruan Tinggi tidak sama dengan proses pembelajaran di sekolah. Pembelajaran di Perguruan Tinggi tidak hanya sekedar pemberian materi, topik ataupun konsep-konsep yang strategis, tetapi juga harus memberikan pengalaman belajar yang memungkinkan berkembangnya kemandirian mahasiswa untuk belajar. Selain itu, 
belajar di perguruan tinggi menuntut proses pembelajaran berpusat pada mahasisswa Student Centered Learning (SCL). Sehingga menuntut mahasiswa lebih banyak belajar, bekerja, dan memahami. Untuk itu, diperlukan adanya kemauan mahasiswa serta semangat yang maksimal agar mahasiswa mampu menyelesaikan tugas nya secara mandiri maupun kelompok.

Salah satu faktor yang dapat menunjang kemandirian mahasiswa dalam belajar adalah ketersediaan sumber belajar yang memadai. Sumber belajar ini bisa berupa buku, modul, serta sumber internet seperti jurnal nasional maupun internasional. Selain itu, mahasiswa juga dituntut untuk mampu belajar secara kelompok dalam menyelesaikan permasalahan yang diberikan oleh dosen.

Pada sebuah universitas terdapat beberapa fakultas, sedangkan dalam satu fakultas terdiri dari atau sama dengan satu jurusan program studi. Pada universitas muhammadiyah sumatera utara memiliki sembilan fakultas salah satunya adalah fakultas keguruan dan ilmu pendidikan. Sedangkan pada fakultas tersebut salah satu jurusan yang menjadi favorit yaitu pendidikan matematika. Yang memiliki visi menjadikan program studi pendidikan matematika yang unggul dalam membangun peradaban bangsa dengan mengembangkan ilmu pengetahuan teknologi dan sumber daya manusia berdasarkan Al-Islam dan kemuhammadiyahan di tingkat nasional.

Menurut Batubara (2017) matematika merupakan salah satu pembelajaran yang dipelajari di sekolah dan mempunyai peranan penting dalam kehidupan sehari-hari yang memiliki banyak cabang mulai dari aljabar, statistik, hingga kalkulus. Matematika dengan berbagai peranannya menjadikannya sebagai ilmu yang sangat penting, dan salah satu peranan matematika adalah sebagai alat berpikir untuk mengantarkan peserta didik memahami konsep matematika yang sedang dipelajarinya. Mata kuliah pada jurusan pendidikan matematika terdiri dari mata kuliah umum (MKU), mata kuliah khusus (MKK), mata kuliah dasar umum (MKDU). Kalkulus Peubah Banyak merupakan bagian dari mata kuliah khusus (MKK). Mata kuliah ini merupakan mata kuliah yang ada pada Kurikulum KKNI. Materi perkuliahan Pada mata kuliah ini materinya tidak terstruktur menurut kurikulum yang ada. Materi-materi pada kalkulus peubah banyak merupakan gabungan dari kalkulus diferensial dan kakulus integral namun pembahasannya lebih mendalam. Saat mengajar mata kuliah kalkulus peubah banyak banyak peneliti temui mahasiswa yang belum mengerti materi atau pokok bahasan sebelumnya sehingga dosen harus mengajarkan sejak awal bagaimana konsep materi yang akan dipelajari. Misalnya banyak mahasiswa yang belum memahami bagaimana menggambar bangun ruang pada koordinatnya. Mahasiswa juga masih belum memahami bagaimana mengintegralkan sebuah fungsi untuk integral pertama.

Hal ini membuat tersitanya banyak waktu hanya untuk mengulang pembahasannya sebelumnya. Sedangkan materi yang dipelajari pada kalkulus peubah banyak sangat mendalam. Mahasiswa juga harus dituntun dan selalu diberi penjelasan oleh dosen. Mereka cenderung masih memahami jenis soal yang telah dibahas sebelumnya, sedangkan untuk soal yang diubah sedikit bentuknya mahasiswa sudah tidak mengerti.

Ketimpangan-ketimpangan seperti ini harus dilakukan perubahan model pembelajaran di dalam kelas. Salah satu model pembelajaran yang sesuai untuk mengatasi masalah ini yaitu model pembelajarn discovery learning.Model pembelajaran ini merupakan model pembelajaran yang menuntuk mahasiswa untuk mandiri namun masih di lakukan binaan dari dosen.

Pembelajaran melalui penemuan (Discovery Learning) memiliki konsep belajar yang baik. Menurut Bruner tujuan strategi discovery learning memberikan kesempatan kepada muridnya untuk menjadi seorang problem solver, scientist, historin atau ahli matematik. Melalui kegiatan tersebut, peserta didik akan menguasai materi, mampu menerapkan, serta 
menemukan hal-hal yang bermanfaat bagi dirinya. Belajar melalui penemuan meliputi enam langkah berikut, yaitu: (1) stimulation (stimulasi/pemberian ragsangan, (2) problem statement (penyataan/identifikasi masalah), (3) data collection (pengumpulan data), (4) data processing (pengolahan data), (5) Verifikasi (Pembuktian) (6) generalization (menarik kesimpulan atau generalisasi).

Menurut Euphony (2010) di Turki menyatakan bahwa "Discovery learning is one of the pedagogic strategies which reduce teachers' direct instruction and have students construct knowledge on their own". Hal ini menunjukan bahwa discovery learning dapat mengembangkan segala potensi yang dimiliki siswa saat pembelajaran. Menurut Hosnan (2014:280) Belajar penemuan merupakan salah satu model pembelajaran yang digunakan dalam pendekatan kontruktivisme modern. Pada belajar penemuan siswa didorong untuk belajar sendiri yaitu melalui keterlibatan aktif dengan konsep-konsep dan prinsip-prinsip. Tugas guru adalah mendorong siswa agar mempunyai pengalaman dan melakukan eksperimen dengan memungkinkan mereka menemukan prinsip-prinsip atau konsepkonsep bagi diri mereka sendiri.

Tujuan Pembelajaran discovery learning, menurut Hosnan (2014:284) yaitu: a) Siswa memiliki kesempatan untuk terlibat aktif dalam pembelajaran; b) Siswa belajar menemukan pola dalam situasi konkret maupun abstrak serta dapat meramalkan informasi tambahan yang diberikan oleh guru; c) Siswa belajar merumuskan strategi tanya jawab yang tidak rancu dan menggunakan tanya jawab untuk memperoleh informasi yang bermanfaat; d) Membantu siswa membentuk cara kerja bersamayang efektif, saling berbagi informasi, serta mendengar dan menggunakan ide-ide orang lain; e) Ketrampilan-ketrampilan konsepkonsep dan prinsip-prinsip yang dipelajari lebih bermakna; dan f) Ketrampilan yang dipelajari lebih mudah ditransfer untuk aktivitas baru dan diaplikasikan dalam situasi belajar yang baru.

Menurut Hosnan (2014) dalam pelaksanaan model discovery learning di kelas, ada beberapa prosedur yang harus dilaksanakan dalam kegiatan belajar mengajar: a) pemberian rangsangan; b) identifikasi masalah; c) mengumpulan data; d) pengolahan data; e) pembuktian; dan f) menarik kesimpulan.

Hasil belajar mahasiswa tidak hanya dipengaruhi oleh umpan balik hasil ujian dan tugas saja tetapi banyak faktor yang lain, misalnya: metode dan model pembelajaran yang digunakan. Menurut Dachi (2017) menyatakan bahwa ada lima macam hasil belajar dari peserta didik yaitu bentk tertulis, penugasan, hasil karya, dan pengumpulan hasil kerja mahasiswa. Berdasarkan uraian di atas maka peneliti tertarik untuk melakukan Penelitian Eksperiman dengan mencari efektifitas model pembelajaran discovery learning terhadap hasil belajar mahasiswa mata kuliah kalkulus peubah banyak FKIP UMSU.

\section{METODE}

Jenis penelitian ini adalah penelitian eksperimen (Pre-Eksperimental Design) dengan menggunakan model One-Group Pretest-posttest Design. Populasi dari penelitian ini ada 5 (lima) kelas jurusan pendidikan matematika semester tiga. Yang berjumlah lebih kurang 180 orang mahasiswa. Sedangkan yang menjadi sampel pada penelitian ini adalah dua kelas yaitu kelas pagi A dan pagi B Prodi Pendidikan Matematika Fakultas Keguruan dan Ilmu Pendidikan Universitas Muhammadiyah Sumatera Utara tahun ajaran 2017/2018 yang dipilih secara acak. Dalam penentuan sampel peneliti melakukan tes awal untuk melihat tingkat kehomogenan setiap kelasnya. Berdasarkan tes awal tersebut peneliti mengasumsikan bahwa ke lima kelas tersebut homogen, sehingga peneliti berkesimpulan hanya mengambil dua kelas dari delapan kelas secara acak (Cluster Random Sampling).

Adapun intrumen untuk penelitian ini adalah berupa tes essay yang diberikan kepada mahasiswa, dan juga observasi atau pengamatan yang dilakukan oleh peneliti selama 
penelitian berlangsung terhadap keaktifan mahasiswa, kreativitas mahasiswa dan motivasi mahasiswa. Untuk membuktikan hipotesis dan menjawab permasalahan dalam penelitian ini dilakukan uji korelasi parsial untuk menentukan hubungan antara variabel bebas dengan variabel terikat, uji korelasi ganda untuk menentukan hubungan variabel bebas dengan variabel terikat, uji statistik $t$-fisher untuk mengetahui pengaruh antara variabel bebas dengan variabel terikat, uji determinasi untuk menentukan persentase pengaruh varaibel bebas terhadap variabel terikat.

\section{HASIL DAN PEMBAHASAN}

Penelitian ini terdiri dari variabel yaitu hasil model discovery learning, pre tes dan post test. Dari pemeriksaan yang telah dilakukan terhadap data, seluruh data yang masuk memenuhi syarat untuk diolah dan dianalisis. Secara singkat dapat dinyatakan bahwa deskripsi data ini mengungkapkan informasi tentang skor tertinggi, skor terendah, rata-rata, standard deviasi, dan banyaknya data. Berdasarkan hasil uji statistik maka diketahui untuk pre test dengan mean 60.49 dengan standar deviasi 8,50, sedangkan untuk post tes dengan mean 80.02 dengan standar deviasi 9,071. Untuk nilai minimum aktivitas adalah 50 nilai maximum 80, sedangkan nilai minimum untuk tes 70 sedangan nilai maximum 95.

Hasil Uji Deskripsi Data Penelitian

Deskripsi hasil penelitian yaitu nilai rata-rata aktivitas pembelajaran matematika menggunakan model pembelajaran discovery learning adala pre test 60.49 dengan standar deviasi 8,50 . Selain itu pula diperoleh hasil nilai post tes yang mempunyai rata-rata 80.02 dengan standar deviasi 9,071.

Uji Normalitas

Berdasarkan dari hasil penelitian, uji normalitas hasil belajar siswa dalam pokok bahasan kalkulus peubah banyak dapat dilihat pada tabel dibawah ini:

Tabel 1. Hasil Tests of Normality

\begin{tabular}{|c|c|c|c|}
\hline & & Pre test & Post Tes \\
\hline $\mathrm{N}$ & & 41 & 41 \\
\hline \multirow[t]{2}{*}{ Normal Parameters ${ }^{\mathrm{a}, \mathrm{b}}$} & Mean & 60.49 & 80.02 \\
\hline & Std. Deviation & 8.500 & 9.071 \\
\hline Most Extreme Differences & Absolute & .190 & .153 \\
\hline & Positive & .180 & .153 \\
\hline & Negative & -.190 & -.108 \\
\hline Kolmogorov-Smirnov Z & & 1.217 & .978 \\
\hline Asymp. Sig. (2-tailed) & & .103 & .294 \\
\hline
\end{tabular}

a. Test distribution is Normal.

b. Calculated from data.

Dari tabel dapat kita lihat untuk nilai Sign aktivitas pembelajaran dengan discovery learning $=0.103$, dan Sign Tes $=0.294$. Sehingga diperoleh hasil tes dengan pembelajaran discovery learning 0,294>0,05 maka tolak Ho dan terima Ha, disimpulkan bahwa pembelajaran dengan discovery learning berdistibusi normal.

Uji Linearitas Regresi

Hubungan yang linier antara variabel dapat diketahui dari persamaan garis regresi yang dibentuk dari setiap variabel dan dapat dilihat dari tabel berikut ini: 
Tabel 3. Uji Regresi Linier

\begin{tabular}{|c|c|c|c|c|c|c|c|}
\hline \multicolumn{8}{|c|}{ ANOVA Table } \\
\hline & & & $\begin{array}{l}\text { Sum of } \\
\text { Squares }\end{array}$ & df & Mean Square & $\mathrm{F}$ & Sig. \\
\hline \multirow{5}{*}{$\begin{array}{l}\text { Pre tes } \\
* \text { post } \\
\text { tes }\end{array}$} & \multirow{3}{*}{$\begin{array}{l}\text { Between } \\
\text { Groups }\end{array}$} & (Combined) & 580.569 & 10 & 58.057 & .865 & .574 \\
\hline & & Linearity & 359.318 & 1 & 359.318 & 5.354 & .028 \\
\hline & & $\begin{array}{l}\text { Deviation from } \\
\text { Linearity }\end{array}$ & 221.251 & 9 & 24.583 & .366 & .942 \\
\hline & \multicolumn{2}{|c|}{ Within Groups } & 2013.333 & 30 & 67.111 & & \\
\hline & \multicolumn{2}{|l|}{ Total } & 2593.902 & 40 & & & \\
\hline
\end{tabular}

Berdasarkan tabel dapat dilihat dari nilai $\mathrm{F}$ table dan $\mathrm{F}$ hitung. Pada $\mathrm{F}$ hitung sebesar 0.366, sedangkan $\mathrm{F}$ table dilihat dari nilai df $(9 ; 30)$ artinya pada Tabel $\mathrm{F}$ diperoleh nilai 2,21. Dari hasil diperoleh bahwa $F$ hit $=0.366$, sedangkan $F$ tab $=2.21$. ini berarti bahwa $F$ hit < F tab. Maka H0 ditolak, dan Ha diterima. Sehingga dapat disimpulkan bahwa data bersifat berdistribusi linier.

Pengujian Hipotesis

Uji Pengaruh Model Discovery Learning Terhadap Hasil Belajar Mahasiswa (Uji T) Hipotesis:

Ho: tidak adanya pengaruh yang efektif terhadap hasil belajar mahasiswa matematika menggunakan Model pembelajaran discovery learning

Ha: adanya pengaruh yang efektif terhadap hasil belajar mahasiswa matematika menggunakan Model pembelajaran discovery learning

Berdasarkan hasil perhitungan untuk nilai $\mathrm{T}_{\text {hitung }}=3.940$ dan nilai $\mathrm{T}_{\text {tabel }}=1,684$ berarti $\mathrm{T}_{\text {hitung }}>\mathrm{T}_{\text {tabel }}$ maka $\mathrm{H} 0$ ditolak, hal ini menunjukan adanya efektivitas pembelajaran matematika menggunakan Model discovery learning terhadap hasil belajar mahasiswa mata kuliah kalkulus peubah banyak.

Peningkatan Hasil Belajar Mahasiswa Setelah Mendapatkan Pembelajaran Dengan Model Discovery Learning

Peningkatan hasil belajar dapat dilihat dari nilai rata-rata mahasiswa mata kuliah kalklus peubah banyak, yaitu dilihat dari tes hasil belajar mahasiswa yaitu mengalami peningkatan dari rata-rata pre test 60,49 sedangkan untuk hasil belajar (post test) setelah mendapat pembelajaran discovery learning sebesar 80,02. Maka mengalami kenaikan sebesar 20,53. Maka dapat disimpulkan terdapat peningkatan hasil belajar mahasiswa setelah mendapatkan pembelajaran dengan model discovery learning mata kuliah kalkulus peubah banyak.

\section{KESIMPULAN}

1. Berdasarkan hasil penelitian menunjukkan bahwa terdapat adanya efektivitas pembelajaran matematika menggunakan Model discovery learning terhadap hasil belajar mahasiswa mata kuliah kalkulus peubah banyak.

2. Peningkatan hasil belajar juga dapat dilihat dari nilai rata-rata mahasiswa mata kuliah kalklus peubah banyak, terdapat peningkatan hasil belajar mahasiswa setelah mendapatkan pembelajaran dengan model discovery learning mata kuliah kalkulus peubah banyak se3besar 20,53. 


\section{DAFTAR PUSTAKA}

Batubara, I. H. 2017. Peningkatan Kemampuan Berpikir Kritis Matematis Melalui Model Pembelajaran Berbasis Masalah Berbantuan Autograph Dan Geogebra Di SMA Freemethodist Medan. Kumpulan Jurnal Dosen Universitas Muhammadiyah Sumatera Utara, V(6). 97-104.

Batubara, I. H. 2017. Peningkatan Kemampuan Pemahaman Konsep Matematis Melalui Model Pembelajaran Berbasis Masalah Berbantuan Autograph Dan Geogebra Di Sma Freemethodist Medan. MES (Journal of Mathematics Education and Science). 3(1). 47-54.

Dachi, S. W. 2017. Upaya Meningkatkan Hasil Belajar Matematika Melalui Strategi Belajar Small Group Work pada Mahasiswa Jurusan Matematika Fakultas Keguruan dan Ilmu Pendidikan Universitas Muhammadiyah Sumatera Utara. Edutech: Jurnal Ilmu Pendidikan dan Ilmu Sosial, 3(1), 109-116.

Euphony. 2010. The Effectiveness Of Inductive Discovery Learning in 1:1 Mathematics Classroom. Proceedings of the 18th International Conference on Computers in Education, Malaysia,743-747.

Hosnan. 2014. Pendekatan Saintifikdan Kontekstual dalam Pembelajaran Abad21. Jakarta: Galian Indonesia.

Wahyuni, S. 2012. Perbedaan Hasil Belajar Matematika Siswa dengan Menggunakan Strategi Menggunakan Strategi Student Led Review Session dengan Metode Konvensional di SMP Muhammadiyah 57 Medan. FKIP UMSU. 